\title{
Transcriação no Sermões de Júlio Bressane: interações de literatura, pintura e oralidade ${ }^{1}$
}

\section{Resumo:}

Analiso trechos do filme Sermões: A História de Antônio Vieira (1989) de Júlio Bressane abordando pares de opostos, elementos que repercutem a vibração e a vertigem barroca, por exemplo: som e silêncio; cheio e vazio. Coloco em debate o processo de transcriação que permite a Bressane transitar por literatura e pintura, com ênfase na oralidade. A voz de Vieira com suas profecias e sermões conduz o cineasta a um trabalho com imagens que oferece também uma cartografia da literatura luso-brasileira, bem como da cultura.

Palavras-chave: Júlio Bressane, Antonio Vieira, transcriação, tradução intersemiótica, oralidade no cinema

${ }^{1}$ Uma versão preliminar deste trabalho, com o título de "Sermões de Júlio Bressane: A Vertigem Barroca, A Voz Repercutida", foi apresentado no XIX Encontro Socine de Estudos de Cinema e Audiovisual na sessão: Cinema Experimental Brasileiro em 21 de out. 2015, seu título é uma referência direta a Jerusa Pires Ferreira (2005) em que discute a voz repercutida, a expressão é dela. Este artigo integra um projeto novo de pesquisas, que desenvolvo desde 2016, intitulado "O Cinema de Júlio Bressane (2006-2016): Intermidialidade da Tradução, Interações com a Literatura e a Pintura", que orienta as publicações desde Sousa (2016), bem como esta versão que foi aprovada para a $6^{a}$ edição das Jornadas de Língua Portuguesa e Culturas Lusófonas da Europa Central e de Leste, da Universidade Jagellónica de Cracóvia. 


\begin{abstract}
:
Transcreation at Sermões by Júlio Bressane: Interactions of Literature, Paintings and Orality

This article analyses some sequences of Sermões: A História de Antônio Viei$r a$, film by Júlio Bressane released in 1989, discussing elements that repercute baroque's vibration and vertigo, as well as opositions in filmaking style such as the presence of: sound and silence; overflow and emptiness etc. Intending to debate the transcreation process (CAMPOS, 1992) which makes Bressane's film pass through literature and paintings, with an enphasize on oral poetry. The voice of Vieira with his prophecies and speechs leads the filmmaker to images offering a cartography of portuguese-brazilian litterature and culture.
\end{abstract}

Keywords: Julio Bressane, Antonio Vieira, transcreation, intersemiotic translation, orality's cinema

Em 2019, Sermões, segunda tentativa declarada de tradução intersemiótica realizada por Júlio Bressane completa 30 anos. Novamente, coloca-se diante de nós o problema da tradução na forma daquilo que ela não é: importante.

A tradução não é importante, seja lá o que essa palavra signifique nos dias de hoje. Em meus textos recentes, em especial, meu Poética de Júlio Bressane (Sousa, 2015), tenho abordado o problema do apagamento da tradução nos debates universitários, aliás, nesse livro, durante sua revisão, tomei todo o cuidado para eliminar a palavra "importante”, que ali aparece pouquíssimas vezes referida por mim (p. 69, na forma de verbo).

Ao lado desse apagamento, acrescente-se os temas relacionados como a ideia de barroco, linguagem e forma, os quais sempre procurei debater apontando possibilidades para pensar saídas epistemológicas, depuramentos de termos e palavras: "importante" é um deles, pois marca um falso problema. Interessa aqui discutir e teorizar alternativas a dicotomias desgastadas como sentido versus forma, conteúdo versus abstração, mímesis versus semiosis ${ }^{2}$.

${ }^{2}$ Tudo isso já teve desenvolvimentos como o artigo publicado recentemente, em francês (Idem, 2017) e no projeto de pesquisas já referido. 
Há um apagamento. De um lado, na forma de se referir, por exemplo, evitando o termo transcriação. Do outro, ao ignorar o próprio problema que é traduzir o trabalho com a linguagem, a qual, nesta proposta de relativização epistemológica, levando em conta nuances do contemporâneo, já não é colocada em termos de signo. Assim, a reflexão nos conduzirá imediatamente às elaborações de Henri Meschonnic (2010) que pensa a noção de poético como algo que não se reduz à estilística nem ao signo.

Tenho procurado propor análises sobre o problema da tradução ou melhor, da transcriação na filmografia de Júlio Bressane, pensando-o como um processo que lhe permite abordagens inventivas e ao mesmo tempo o trânsito por linguagens diferentes, por outras artes. Em mais de um momento, exponho o que estamos abordando como tradução intersemiótica, ou melhor, transcriação (Sousa, 2015, 2016, por ex.). Faço breve resumo a seguir.

\section{A Transcriação, a Poética do Traduzir}

Roman Jakobson situa em um texto curto o problema da impossível tradução de textos poéticos numa perspectiva moderna, aquela de uma tradução intersemiótica ou transmutação.

O linguista russo lembra a natureza específica da poesia. Ressalta a presença constante da paronomásia e uma construção feita para criar significados muito próprios, inferindo que esse tipo só pode se realizar como transposição criativa:

Em poesia, as equações verbais são elevadas à categoria de princípio construtivo do texto [...] em suma, todos os constituintes do código verbal - são confrontados, justapostos, colocados em relação de contiguidade de acordo com o princípio de similaridade e de contraste, e transmitem assim uma significação própria. A semelhança fonológica é sentida como um parentesco semântico [...] a paronomásia reina na arte poética; quer esta dominação seja absoluta ou limitada, a poesia por definição é intraduzível. Só é possível a transposição criativa: transposição intralingual - de uma forma poética a outra -, transposição interlingual ou, finalmente, 
transposição intersemiótica - de um sistema de signos para outro, por exemplo, da arte verbal para a música, a dança, o cinema ou a pintura. (Ibid.: 72)

Note-se que é Jakobson quem chama as outras artes de sistemas de signos, termo que também designa a linguagem. Por sua vez, Haroldo de Campos elabora o conceito de transcriação, reunindo exemplos e desenvolvendo procedimentos teóricos e práticos mais detalhados para, assim como Jakobson, opor-se à atividade tradutória como um gesto mimético e conteudista. Ou seja, remete não à língua do original, mas ao seu trabalho com a linguagem, à sua poética:

Numa tradução dessa natureza, não se traduz apenas o significado, traduz-se o próprio signo, ou seja, sua fisicalidade, sua materialidade mesma (propriedades sonoras, de imagética visual, enfim tudo aquilo que forma, segundo Charles Morris, a iconicidade do signo estético, entendido por signo icônico aquele "que é de certa maneira similar àquilo que ele denota”). O significado, o parâmetro semântico, será apenas e tão-somente a baliza demarcatória do lugar da empresa recriadora. Está-se, pois, no avesso da chamada tradução literal (Campos, 1992: 35).

Campos analisa soluções de outros tradutores e estudiosos do tema, por exemplo, ao expor a noção de tom e ritmo do original via Ezra Pound ou, ainda, ao comentar textos que alcançaram realizar transcriações. Chega a nomear o processo como "traduzir a forma"3.

Cabe reter daí que a transcriação se dá como transposição criativa de um sistema de signos a outro, de uma linguagem a outra, apoiando-se em um estudo do texto original, no sentido de compreender sua poética, que elementos são colocados em jogo, provenientes de uma exploração da linguagem (literatura e pintura, por exemplo) ou advindos da própria cultura em que se inserem.

No diálogo constante entre Bressane e o crítico literário e poeta Haroldo de Campos, é possível entrever um ir além, uma percepção

${ }^{3}$ Reiteradas vezes, o crítico afirma que se trata de um processo de traduzir a forma, ver por exemplo Campos, 1977 : 98 e, sobretudo: 101, em que analisa a tradução do ludoviscense Odorico Mendes. 
do que é inventivo como reverberação e movimento. O olhar volta-se também para a presença da oralidade, aproveitando sugestão de outro teórico da tradução que é Henri Meschonnic, adaptando-os, evidentemente, ao cinema. Lembro a elaboração teórica de Meschonnic segundo a qual a poética do traduzir desempenha um papel de contra-histeria, ou seja, ela insere o corpo na linguagem.

Em sua crítica do ritmo, Meschonnic afirma que é necessário se interrogar sobre o que constrói a literatura. Sobretudo em relação aos textos poéticos, entende a oralidade como uma contra-histeria, ou seja, como o que insere o corpo na linguagem (1993: 104), isto é, propõe pensar o papel da oralidade na tradução a partir de um "efeito de linguagem sobre o corpo", como uma reversão de noções pertencentes à psicanálise (a qual, por sua vez, extrai uma linguagem onde há uma descarga do corpo):

L'oralité intervenant comme une contre-hystérie, une forme d'hystérie qui mettrait le corps dans le langage. Le maximum possible du corps, et de son énergie. Comme rythme. [...]

L'oralité serait, non une décharge, mais une charge pulsionnelle maximale. Non une pathologie, comme l'hystérie, mais son inverse. La même force, mais tournée du corps vers le langage au lieu d'être tournée du langage vers le corps. Et ainsi l'efficacité maximale du langage. (Meschonnic, 1993: 104).

Exemplo disso, oferece em seu comentário sobre a tradução dos silêncios e repetições que, em Tchékhov (1999: 395 e 405, por exemplo, em texto não incluído na tradução brasileira), desempenham papel fundamental para a análise das traduções francesas de Tchaika (A Gaivota) e em especial aquela realizada por Antoine Vitez.

\section{As Vozes de Vieira}

Sendo assim, proponho analisar trechos de Sermões: A História de Antônio Vieira de Júlio Bressane, discutindo elementos que repercutem a vibração e a vertigem barroca: a voz e o silêncio; o cheio e o vazio etc. 
O silêncio no cinema de Bressane é abordado com profundidade pela primeira vez nas leituras de Bernardet (1991) e Teixeira (1995 e 2003), que discutem em diálogo teórico: de um lado, o laconismo das imagens nos primeiros filmes do diretor; e, de outro, o soterramento de referências que depois se metamorfoseia num colapso do tempo nas referências, em tudo aquilo que Bressane aborda na construção de seus filmes.

Direi pegando a deixa dos dois autores que o silêncio se presentifica de modos diferentes na filmografia. Embora domine tramas diversas como São Jerônimo ou O Rei do Baralho, não é propriamente o mesmo que se repete, afinal, o silêncio muda. De certo, faz-se presente e paradoxal no filme com o padre Antônio Vieira em que a voz desempenha papel fundamental para que se trave contato com a personagem.

O silêncio tem vez na voz, Meschonnic dirá algo parecido, há "sempre voz no silêncio, e silêncio na voz..." (Meschonnic, 1993: 84). O barroco em Sermões vem criar um efeito de paradoxo com o vazio, figura antagônica a esse tipo de poética. Figura corrente da arte barroca, a voz vê diante de si a dissolução entre ela e o silêncio. O silêncio também está na sequência de abertura de Sermões, que inicia com a morte do padre: fim que não é fim. O padre recita sobre a morte como o medo do silêncio, o medo da cessação, o perigo de que cessem o movimento, as dobras, a vibração e a vertigem barrocas.

No meu modo de ver, o cineasta transita por espaços do vazio do mesmo modo como atravessa o barroco. A questão para ele, é o trânsito, o atravessamento por figuras de estilo como o vazio e o cheio, o barroco e o naturalismo, bem como de culturas diferentes.

\section{2}

Nas duas primeiras sequências que se pretende discutir aqui, ouve-se algum texto repetidas vezes: a primeira começa com o plano em que Vieira está rezando em frente a um altar e o ouvimos dizer "A novidade do novo mundo...", duas ou três vezes, bem baixo, antes de ouvir o sermão em off e por inteiro; a segunda, antecipa um trecho de "As Lágrimas de Heráclito", o padre está diante de uma luminária. 
Bressane imbrica uma fala que termina por "fomos pó...", com o início do que vem a ser um excerto de "As Lágrimas de Heráclito", de Vieira:

Quem conhece chora, quem conhece mais ri. Se a pequena dor é a causa do choro, por que a grande dor não há de ser a causa do riso? Se a pequena dor solta lágrimas, a grande dor as congela e seca. Dor que pode sair pelos olhos não é grande dor.

Se nesses dois momentos tem-se o áudio dobrado como imagem, no terceiro, na performance de Haroldo de Campos e Alberto Marsicano, há a própria imagem dobrada. Temos a figura da mise-en-abîme, que é ampla e sugestivamente explorada por Ismail Xavier (2006). Essa construção em abismo, e aqui refiro ao sentido da velha heráldica medieval (Pavis, 2008), arte de brasões, é realizada com o efeito de dois espelhos um em frente ao outro.

As duas sequências mencionadas acima se confundem com aquela terceira imagem, que é levada para o som: a de uma reprodução dessa figura barroca que é a mise-en-abîme. Trata-se, pois, de uma construção que, ao se repetir ao infinito, se dobra e desdobra em outras imagens, como se encenasse a procura de um filme, a própria transcriação: a procura da vertigem barroca, daquele barroco vibrante do padre e que também se faz presente como um discurso de invenção, por exemplo, na elaboração teórica e na poesia haroldiana.

$\mathrm{Na}$ expressão do cineasta, temos aí elementos que ajudam a remeter ao "signo" que se pretende traduzir, signo aí entendido como a reverberação de Antônio Vieira na cultura ${ }^{4}$. Haverá outros tais como as escadas em caracol e os pisos arlequinados, ou ainda, o recurso aos espelhos na fala de Vieira com outros padres ou nos ambientes da realeza. Destaco o traço iconográfico nas vestes vermelhas que lembram pinturas em que São Jerônimo aparece vestido de cardeal.

${ }^{4}$ A meu ver, Bressane (2000) utiliza-se do termo com sentido diverso do linguísto-estrutural no artigo "O Signo Jerônimo", ou seja, aborda a reverberação do intelectual nas culturas brasileira e ocidental. 
O processo de transcriação permite a Bressane transitar por literatura e pintura, com ênfase na oralidade. Ocorre, por exemplo, quando remete à parequese, figura constante dos sermões do padre, numa paronomásia audiovisual com pinturas de Velázquez e Botticelli: o momento do "Vieira venera Vênus". Ou ainda, à voz profética que ecoa pelo filme todo, com a sua dimensão utópica e de uma busca: de um lado, a restauração via Sebastianismo; de outro, a transcriação do signo Vieira, ou seja, sua amplitude, sua reverberação na cultura, para além de uma cinebiografia.

No início, Bressane segue a sugestão do poeta das Galáxias, que também atuou como assessor nesse filme, e vai transformar em imagem, a "paronomásia etimológica (parequese) representada pela sequência léxica Vieira / Venera / Vênus", conjunção que projeta, citando Campos:

no nome do pregador luso-brasileiro, pela via da concha de peregrino em forma de pente de Vênus ou da concha em que Afrodite exsurge do mar, o próprio nome da deusa do amor [...] A Vênus nascendo das águas, numa concha (vieira, venera) boticelliana. A Vênus de Velázquez, em repouso, esplendidamente nua. O detalhe arquitetural dessas mesmas conchas, ornato de gosto barroco. Através desse encadeamento imagético, que se completa com o motivo contrastante da "caveira", o tema da beleza (vida) e o tema do luto cadaveroso (morte) são presentificados por Bressane (Campos, 1995: 28-29).

A paronomásia é transcriada logo no início do filme: a câmera percorre um interior barroco, nos mostra uma concha, move-se pelo ambiente até fixar-se em um anjo. O plano seguinte traz a $A$ Vênus no Espelho de Velazquez e O Nascimento de Vênus de Sandro Boticelli. Há pintores dos quais o cineasta vai buscar a luz casos de Rembrant, Vermeer (Vista de Delft), ou os gestos como o José de Ribera, de O Sonho de Jacó, ou ainda, uma performance, como El Peléle de Goya, 
que se pode ver na sequência anterior ao fragmento de "As Lágrimas de Heráclito".

\section{4}

Em Sermões, as performances recorrem ao texto de Vieira para trazer a voz à cena com as impostações de Othon Bastos e seu leve sotaque baiano. A voz aponta para a presença, remetendo à personagem de profunda erudição e ao mesmo tempo, à sua poética vibrante que em tudo traduz o barroco e sua reverberação nas artes e na cultura brasileira.

Há as incorporações de filmes, destaco o fáustico Nosferatu de Murnau, mas que está aí para dar o aspecto de crítica à rapina presente no "Sermão aos Peixes", haveria ainda o elemento "da invenção" com incorporações de Méliès, Dryer, L'Herbier, mas também a presença da literatura brasileira num registro de Lampião, referência maior do cangaço, feito por um mascate, Benjamin Abrahão. Com o Barroco, os elementos de estilo relacionados à invenção ganham espaço, e o filme nos leva a contemplar a passagem por figuras proeminentes da literatura, tais como Gregório de Matos (sugestivamente interpretado por Caetano Veloso), Haroldo de Campos e o seminal Grande Sertão: Veredas de João Guimarães Rosa.

\section{5}

Fundamental em Meschonnic para compreender a poética do traduzir (Meschonnic, 2010), a oralidade permite extrair relações quando a entendemos como presença, gesto e performance (Pires Ferreira, 2007; Zumthor, 2000). Voz e oralidade aí trazem uma percepção do poético, de fazer o texto como performance, ou seja, é algo elaborado para esse fim.

Já falamos da ideia de contra-histeria em Meschonnic. Por sua vez, Zumthor nos diz:

no uso mais geral, performance se refere de modo imediato a um acontecimento oral e gestual [...] Pelo menos, qualquer que seja a maneira pela qual somos levados a remanejar (ou a espremer para extrair a substância) 
a noção de performance, encontraremos sempre aí um elemento irredutível, a ideia da presença de um corpo. Recorrer à noção de performance implica então a necessidade de reintroduzir a consideração do corpo no estudo da obra. (Zumthor, 2000: 45)

Mais adiante ele dirá: “A performance refere-se a um momento tomado como presente. [...] Ela atualiza virtualidades mais ou menos numerosas, sentidas com maior ou menor clareza. Ela as faz "passar ao ato" (Zumthor, 2000: 59).

Voz e oralidade aí trazem uma percepção do poético, há o fazer do texto como performance, de algo que é elaborado para se performar. Meu argumento é que Bressane procura dar uma ideia do corpo intraduzível, que é o corpo desse texto, nas performances do padre, na sua voz, nos gestos e fisionomia que Othon Bastos encarna. Temos o que sugere a inserção do corpo operada na literatura, bem como no recurso à mise-en-abîme.

\section{6}

A voz de Vieira com suas profecias e sermões conduz o cineasta a um trabalho com imagens que pretende também uma cartografia luso-brasileira. A repercussão da imagem do mar coloca sua leitura como signo da viagem em literatura de língua portuguesa: o mar está para ela como o sertão para a literatura brasileira (Lourenço, 2001).

Há a profecia de Bandarra, recitada no começo, mas que ecoa pelo filme todo, com a sua dimensão utópica e de busca de uma restauração via Sebastianismo: o rei encoberto, que viria montado em seu cavalo, para libertar o povo, para nos lembrar de São Jerônimo e Euclides da Cunha. Há a menção ao "Imperador da língua portuguesa", frase célebre de Fernando Pessoa, presente na reflexão de Lourenço (2001) sobre a pátria como miragem...

Volto ao plano em que o padre repete várias vezes a frase "a novidade do novo mundo", como se recitasse poesia concreta. Vieira prossegue e recita em off, na proa de um barco: "a novidade do novo 
mundo é que aqui o pregador não prega a ideia, mas a ideia que prega o pregador".

O plano seguinte traz o mar ao fundo e é Othon Bastos quem vira personagem. Numa conjunção proposital de sua figura girando na tela, ele próprio se torna signo do cruzamento entre cinema e literatura, em clássicos como Deus e o Diabo na Terra do Sol de Glauber Rocha (que recria Grande Sertão: Veredas, mas principalmente alguns traços barrocos de Os Sertões), ou como São Bernardo de Leon Hirzman, enquanto ouvimos o barroco da ária da "Bachiana n. 5", de Heitor Villa-Lobos. Nessa conjunção de Othon Bastos sob o signo de três - Corisco, Paulo Honório, Antônio Vieira - Bressane pretende outra coisa, algo diferente do projeto cinemanovista, ou do diálogo com os cineastas daquele movimento, algo está em foco para além da simples homenagem a Glauber Rocha, eu diria que uma miragem de Brasil.

\section{Referências bibliográficas}

BERNARDET, J.-C. (1991), O Vôo dos Anjos: Bressane, Sganzerla, Brasiliense, São Paulo.

BRESSANE, J. (1997), "Conversa com Júlio Bressane/Miramar, Vidas Secas e o Cinema no Vazio do Texto", Cinemais, 6, Rio de Janeiro, Entrevista a Geraldo Sarno e Carlos Avellar.

BRESSANE, J. (2000), Cinemancia, Imago, Rio de Janeiro.

CAMPOS, H. de (1995), "Vieira/Venera/Vênus" em: Vorobow, B., Adriano, C. (orgs.), Júlio Bressane: Cinepoética, Massao Ohno, São Paulo.

CAMPOS, H. de (1977a), "A Arte no Horizonte do Provável”, em: Campos, H. de, A Palavra Vermelha de Hoelderlin, 4 ed., Perspectiva, São Paulo. CAMPOS, H. de (1977), “A Escrita Paradisíaca” em: Dante Alighieri, 6 Cantos do Paraíso, trad. H. de Campos, Fontana, Rio de Janeiro / Istituto Italiano di Cultura, São Paulo.

CAMPOS, H. de (1992), Metalinguagem \& Outras Metas, 4 ed., Perspectiva, São Paulo.

JAKOBSON, R. (1969), Linguística e Comunicação, Cultrix, São Paulo.

LOURENÇO, E. (2001), A Nau de Ícaro, Companhia das Letras, São Paulo. 
MESCHONNIC, H. (1999), Poétique du Traduire, Verdier, Paris. (Trad. Bras.: Poética do Traduzir, trad. Jerusa Pires Ferreira e Suely Fenerich, Perspectiva, São Paulo 2010).

MESCHONNIC, H. (1993), "L'Oralité, poétique de la voix" em: Rey-Hulman, D. (org.), Pour une anthropologie des voix, Centre de Recherche sur l'oralité / Harmattan, Paris.

PAVIS, P. (2008), “ Mise en Abyme” em: Pavis, P., Dicionário de Teatro, 3 ed., Perspectiva, São Paulo.

PIRES FERREIRA, J. (2007), "Sermão, Vieira, Performance”, Asas da Palavra: Revista de Letras, 10(23), pp. 160-169.

PIRES FERREIRA, J. (2005), "Visages du vent et échos de la voix" em: Filteau, C., L'Espace poétique de Gaston Miron, Pulim, Limoges.

SOUSA, A. C. A. e (2016), "Saint Jérôme de Júlio Bressane: La traduction comme chemin critique", Doletiana: revista de traducció, literatura i arts, 5/6, pp. 1-19.

SOUSA, A. C. A. e (2015), Poética de Júlio Bressane: Cinema(s) da Transcriação, Educ/Fapesp, São Paulo.

TEIXEIRA, F. E. (2003), O Terceiro Olho, Perspectiva/FAPESP, São Paulo.

TEIXEIRA, F. E. (1995), O Cineasta Celerado: A Arte de Se Ver Fora de Si no Cinema Poético de Júlio Bressane, Tese de Doutorado, FFLCH-USP. XAVIER, I. (2006), "Roteiro de Júlio Bressane: Apresentação de uma Poética”, Revista Alceu, 6(12), pp. 5-26, [on-line] http://publique.rdc.puc-rio. $\mathrm{br} /$ revistaalceu/media/alceu_n12_Xavier.pdf - 30.04.2007.

ZUMTHOR, P. (2000), Performance, Recepção e Leitura, Educ, São Paulo. 